\title{
Sustainability Intelligence: Emergence and Use of Big Data for Sustainable Urban Planning
}

\section{Mr. Ben D. Radhakrishnan, National University}

Prof. Ben D Radhakrishnan is currently a full time Faculty in the School of Engineering, Technology and Media (SETM), National University, San Diego, California, USA. He is the Lead Faculty for MS Sustainability Management Program. He develops and teaches Engineering and Sustainability Management graduate level courses. Ben has taught Sustainability workshops in Los Angeles (Army) and San Diego (SDGE). His special interests and research include promoting Leadership in Sustainability Practices, energy management of Data Centers and to establish Sustainable strategies for enterprises. He is an Affiliate Researcher at Lawrence Berkeley National Laboratory, Berkeley, CA, focusing on the energy efficiency of IT Equipment in a Data Centers. As a means of promoting student-centric learning, Prof. Radhakrishnan has successfully introduced games in to his sustainability classes where students demonstrate the 3 s of sustainability, namely, Environment, Economics and Equity, through games. Students learn about conservation (energy, water, waste, equity, etc.) through games and quantifying the results. He has published papers on this subject and presented them in conferences. Before his teaching career, he had a very successful corporate management career working in $R \& D$ at Lucent Technologies and as the Director of Global Technology Management at Qualcomm. He had initiated and managed software development for both the companies in India. Prof. Radhakrishnan holds Masters Degrees (M.Tech, M.S., M.B.A) and Sustainable Business Practices certification from University of California San Diego.

\section{Dr. Jodi Reeves, National University}

Dr. Jodi Reeves is an Associate Professor and Department Chair of Applied Engineering at National University in San Diego, CA. She teaches courses in design engineering, engineering management, and data analytics. Prior to academia, she worked for almost ten years as a quality control manager, engineering project manager, and senior scientist responsible for failure analysis of thin film materials. She invented new quality control tools and supervised interns from local universities and community colleges as part of a $\$ 5.0$ million technical workforce development initiative funded by New York State. She has published diverse articles on topics ranging from engineering education to high temperature superconductors and has spoken at many national and international conferences. Her doctorate in materials science and engineering are from the University of Wisconsin, Madison, and she holds five patents.

\section{Mr. Jeremiah Jack Ninteman, National University}

Mr. Ninteman is a graduate of National University's Master of Science in Data Analytics program in San Diego, Ca. Prior to attending National University, Mr Ninteman earned a B.A. from San Diego Christian College and worked as business analyst in the commercial real estate industry where he acquired an interest in big data and analytics. Mr. Ninteman has since supported the development of business intelligence applications in facility and construction management for the instialltions department of the U.S. Bureau of Naval Medicine and Surgery and currently works as an analytics consultant with Booz Allen Hamilton, Inc., supporting operations research and data science efforts at the U.S. Space and Naval Warfare Systems Command. He hold a B.A., a M.S. and is a Tableau certified associate.

\section{Charles Hahm}


Sustainability Intelligence: Emergence and Use of Big Data For Sustainable Urban Transit Planning

Ben D Radhakrishnan

Jodi Reeves

Charles Hahm

Jeremiah Ninteman

National University, San Diego, CA 


\begin{abstract}
Reducing traffic emissions, especially carbon dioxide $\left(\mathrm{CO}_{2}\right)$, is a major goal of sustainable urban transportation planning since approximately $50 \%$ of the world's population lives in urban areas. In the summer of 2015, an interdisciplinary capstone project at our university integrated sustainable methods to address environmental climate change in urban transportation planning with big data visualization technology.

This paper describes a predictive model approach using traffic data to quantify $\mathrm{CO}_{2}$ emission reductions through alternate transportation methods, thus integrating environmental sustainability principles with urban transportation data analysis. The traffic data is collected by the California State Department of Transportation on the highways of the San Diego metro area. The dynamic predictive model quantifies the $\mathrm{CO}_{2}$ emissions of cars, trains, and buses. Data visualization using Tableau software allows a comparison of different transportation modes and the $\mathrm{CO}_{2}$ emission reduction that can be obtained when alternate transportation methods are used in an urban environment. In the future, this predictive modelling technique and big data visualization dashboard can be used by urban planners and government transportation agencies as a business intelligence tool for environmental sustainability.
\end{abstract}

\title{
Introduction
}

During the Industrial Revolution, the population started to shift from agricultural-based rural and small towns to urban areas where factories were located. The rate of population movement to urban areas increased significantly after World War II, which has put a heavy burden on urban management of environmental resources. In the 1950s and 1960s, the United States focused on the automobile as an important element of transportation. With the rapid economic growth, automobile ownership increased along with the sub-urban growth and housing boom, and gasoline was inexpensive. ${ }^{[1,2]}$ President D. Eisenhower initiated the building of freeways across the US. This scenario was a perfect storm for unlimited and uncontrolled growth of urban automobile driving, thus creating the traffic congestion as we know it now.

It is estimated that an average American commuter spends 38 hours a year stuck in automobile traffic congestion; the cost of the wasted time (economic productivity loss) and the fossil fuels burned is $\$ 121$ billion annually. ${ }^{[3]}$ Figure 1 shows the cities with the worst urban traffic congestion in America, where the big city average is approximately 52 hours a year. 


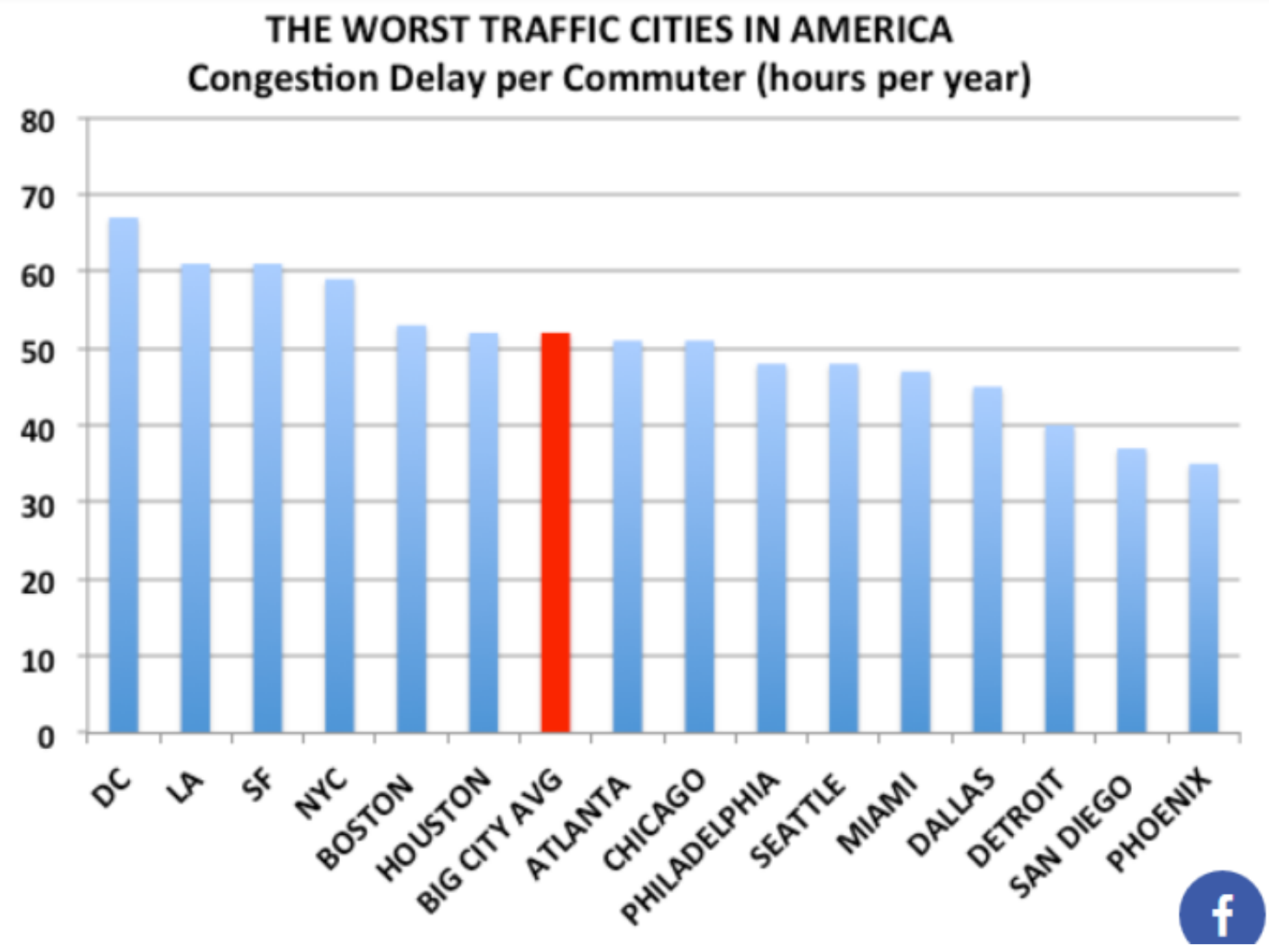

Figure 1. The Worst Traffic Cities in America ${ }^{[3]}$

Traffic congestion is not just an American problem, it is a global problem as well. According to the United Nations World Urbanization Prospects report, urban population grew from $30 \%$ of the world population to $54 \%$ in 2014 and is expected to be $66 \%$ by $2050 .^{[4]}$

Since the 1990's, scientists have traced global warming and climate change to the Green House Gases (GHG) emitted by the fossil fuels burned in the transportation sector. The US transportation sector, which is the movement of people and goods by cars, trucks, trains, ships, airplanes, and other vehicles, emitted 1,802 million metric tons of $\mathrm{CO}_{2}$ according to the Environmental Protection Agency; this is $27 \%$ of all GHG emissions in 2013. ${ }^{[5]}$

Thus from an environmental perspective, pollution due to the burning of fossil fuels in automobiles results in global warming and climate change, where $\mathrm{CO}_{2}$ is the major polluter. From a cost perspective, loss of time in traffic congestion leads to loss of economic productivity. These issues result in environmental degradation, poor economics, and inequity.

According to city planner Dereck Vollmer in his book "Pathways to Urban Sustainability," city planners are currently faced with two options: the status quo of simple up-keep of the current planning policies or changing the models to re-shape the city's infrastructure around sustainable 
environmental practices, like alternate modes of transportation. ${ }^{[6]}$ Vollmer states that the U.S. Center for Disease Control (CDC) has also begun to be involved in the process of city planning. Dr. Christopher Portier, director of the CDC and the National Center of Environmental Health, stated that the CDC needs to get involved because transit planning is now an issue of public health due to increasing emissions. The trends in poor air quality and increased global temperatures have created a dangerous scenario that, if not mitigated, will lead to decreased health among people in urban areas. Portier states that a community can be planned to benefit human health by including multiple modes of public transit.

Urban planners need new resources, processes, and tools to effectively address these transportation issues and their effect on environmental climate change. We are living in a digital world where billions of traffic sensors, smart phones, tablets, personal computers, vehicles, and other urban sensors are generating enormous amounts of data at an extremely high rate. By integrating environmental sustainability principles with data analytics and visualization methods, urban transportation data can be investigated for patterns, predictive models can be created, and different urban transportation scenarios can be analyzed to find environmentally sustainable solutions to global traffic congestion that reduces $\mathrm{CO}_{2}$ emissions and improves human health globally.

\section{Data Sources}

Data for this project comes from the California Department of Transportation's (DOT) annual traffic census which is publically available through the department's web site. ${ }^{[7]}$ The California DOT gathers traffic volumes through the use of electronic counting instruments shown in Figure 2. The device uses sensors running across the roadway to count the number of vehicles that pass over that given section.

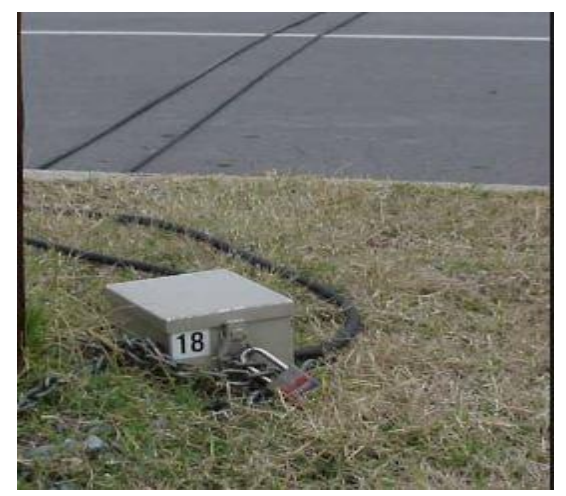

Figure 2 California Traffic Counting Device

The annual average daily traffic, or AADT, is the average count based on the number of days data was collected. The counts only reflect weekday counts, and collections are not made on major federal holidays. ${ }^{[7]}$ Peak hour counts reflect the average maximum hourly counts of the 
given routes. In the San Diego metro areas, these peak times are between the hours of 7:00am and 9:00am and 5:00pm and 7:00pm.

\section{Predictive Modeling}

Before data visualization, the automobile traffic data needs to be converted to greenhouse gas volumes and used in a predictive model. The Federal Highway Administration's Travel Demand Management (FHA TDM) evaluation model was created in 1993 to track traffic congestion with the goal of facilitating air quality programs across the country. This model was based on trip readings of traffic counts to understand where alleviation of traffic congestion is most needed. In 2005, a more accurate $\mathrm{CO}_{2}$ emissions model was created by the EPA based on the FHA TDM model and is known as the COMMUTER model. This model uses historic data with information regarding vehicle count, average speed, average trip distance, and transit mode choice. ${ }^{[8]}$ The result from the model is an estimate of the output of greenhouse gasses emitted over a period of time. The structure of the COMMUTER model is shown in Figure 3 and explained in more detail below.

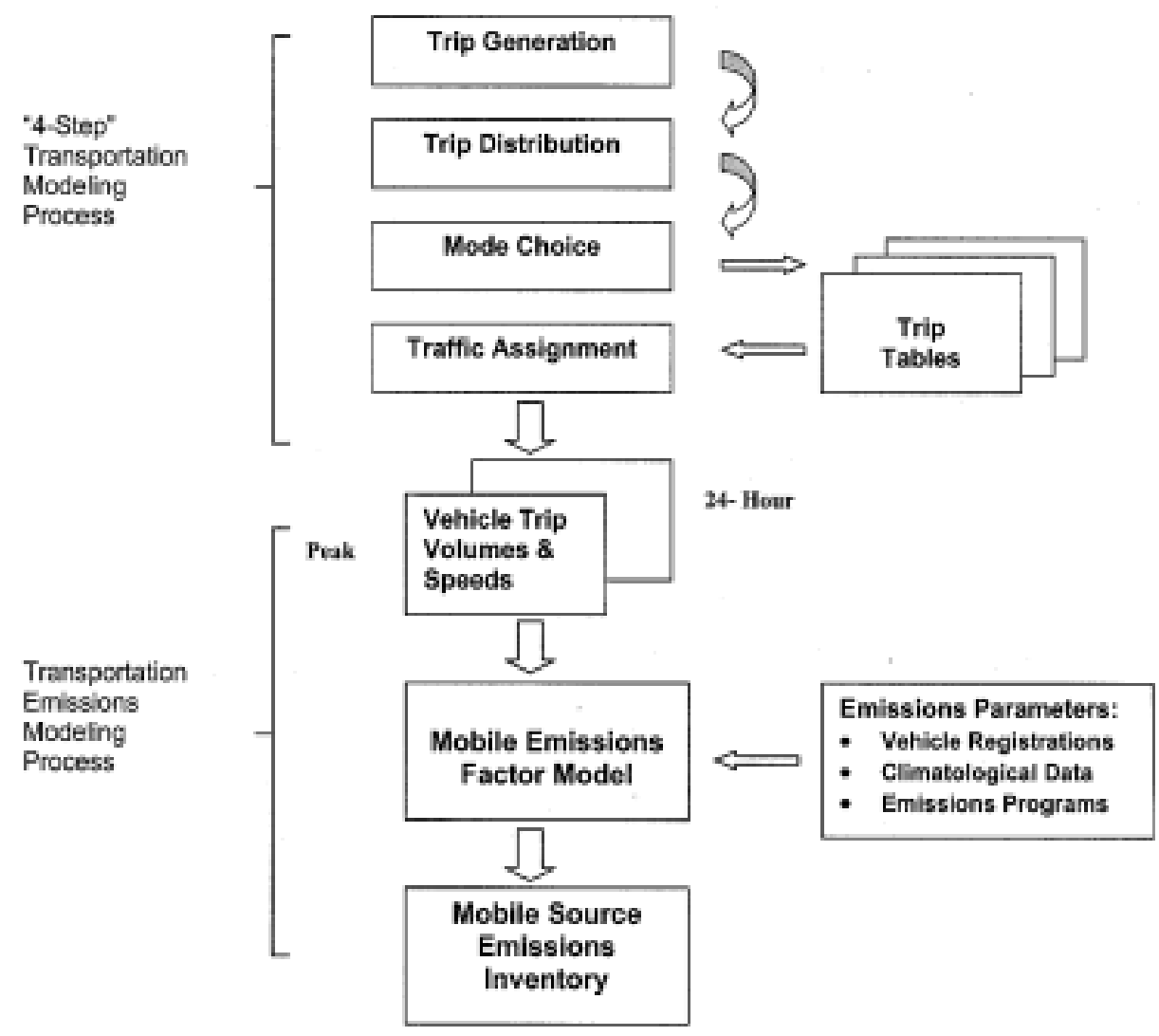

Figure 3: COMMUTER Model Emissions Analysis Process ${ }^{[8]}$ 
The COMMUTER model focuses on four main variables to compute $\mathrm{CO}_{2}$ emission volume. The first step is Trip Generation. This step converts the population, vehicle ownership, and land use factors into an estimate of the number of trips made on average from certain locations. Next the Trip Distribution step is used to determine where each of these trips will take place from. This step involves identifying high traffic areas and the common start and stopping points of these routes. The DOT states that a given urban zone may have well over 1,000 zones of high traffic areas. Following this, the Mode Choice step is used to predict the mode of transportation used. The most common modes are personal auto driver, personal auto passenger, and alternate transit. Once these modes have been established, the model is split to compute different outputs for each vehicle trip. The fourth step is the Traffic Assignment step. This step calculates the volume at which trips are taken in a given area and average speed in which the vehicles are able to travel. With these four steps as inputs to the COMMUTER model, the output is the amount (in tons) of $\mathrm{CO}_{2}$ in peak traffic periods.

In order to apply the COMMUTER predictive traffic model to San Diego area traffic, California DOT's highway sensor data is filtered to exclude all data except that from San Diego County. The resulting model output was used to construct an interactive data dashboard to visualize the $\mathrm{CO}_{2}$ emission volumes from automobile traffic on the most congested San Diego routes. Specifically, the San Diego urban/metropolitan freeway system consists of four major interstate highways (I-5, I-15, I-8 and I-805) and nine other local urban highways, for a total of more than

300 miles of highways. ${ }^{[9]}$ It is estimated that of the 1.4 million workers in San Diego County, $94 \%$ commute and the rest work at home. Of those who commute, $90 \%$ use a truck, car or van to get to work - this resulted in 13.95 million metric tons of GHG emissions in 2012 alone. $^{[10]}$

\section{Traffic Data Visualization and Results}

Figure 7 shows the data dashboard created using Tableau software for visualizing peak traffic in San Diego along the four major traffic routes and analyzing the $\mathrm{CO}_{2}$ emissions along these routes. Alternate transportation modes such as bus and train travel can be added to the model to determine the $\mathrm{CO}_{2}$ reduction by removing automobile traffic off these congested traffic routes.

Item 1 is a numerical summary of the total emissions, in metric tons, of $\mathrm{CO}_{2}$ emitted by traffic on the major automotive routes. Item 2 is horizontal bar chart showing the total $\mathrm{CO}_{2}$ emissions for each individual route. Item 3 is a color-coded geographic map showing highway I-5 in blue, I-15 in green, I-8 in orange, and I-805 in red. Additionally, the size of the colored circles along each route corresponds to the traffic volume at that location at a given time. Larger circles correspond to higher traffic density and thus higher $\mathrm{CO}_{2}$ emissions.

Item 4 includes twelve alternate transit parameters that represent utilization of alternate transit modes of bus travel, train travel, and telecommuting. When non-zero values are entered into the 
twelve transit parameters, the model calculates $\mathrm{CO}_{2}$ emission reduction along each route and adds that value to Item 2 as well as adds the total $\mathrm{CO}_{2}$ emission reduction (in metric tons) to Item 1. Finally, Item 5 is a benchmark tracker of $\mathrm{CO}_{2}$ emission reduction due to utilizing alternate transportation modes.

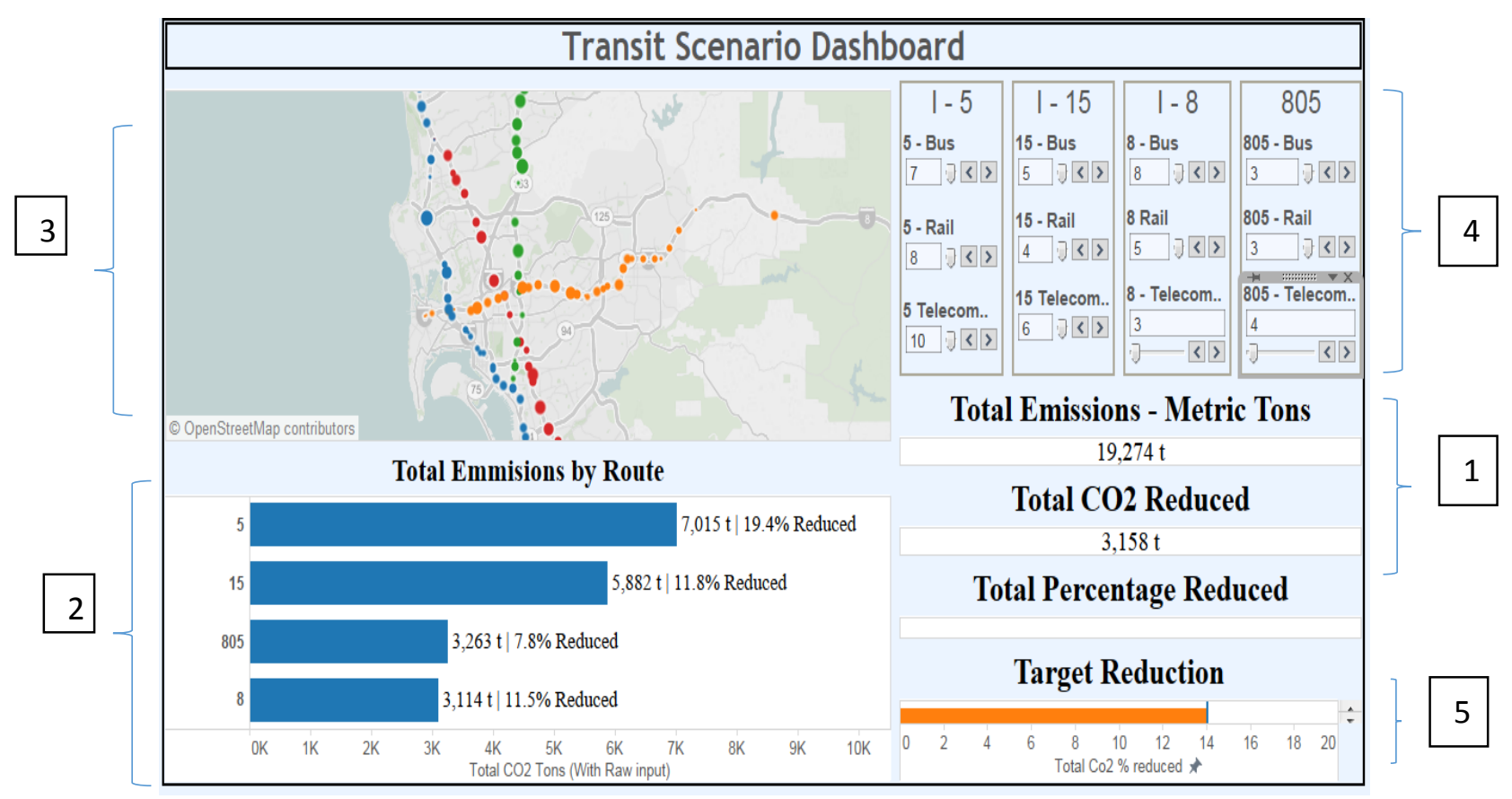

Figure 7: San Diego Area Interactive Alternative Transportation Dashboard

Using this transportation data dashboard, an urban traffic planner can change the percentage of traffic that can be moved from one or more of the four interstates to any of the three proposed alternative transportation methods in Item 4 and then see in real time the $\mathrm{CO}_{2}$ reductions in each scenario in Item 2. The moveable cursor under each alternative is the percentage of traffic moved away from the highway to an alternative mode of transportation. As the planner moves the cursor, the dashboard displays the percentage traffic reduction and also the percentage $\mathrm{CO}_{2}$ reduction. The model automatically calculates the total $\mathrm{CO}_{2}$ reduction towards the example target reduction of 14\%, shown in item 5. Since California's Senate Bill SB 375 set a 14\% target for $\mathrm{CO}_{2}$ reductions by 2020, this target was used as an example in our model demonstrating various modes of transportation that can be employed in the different highways to achieve it as shown in Figure 7.

There are many other ideas to explore in future interdisciplinary capstone projects between MS Sustainability Management and MS Data Analytics students. First, other alternate transportation 
options such as electric vehicles, hybrid vehicles with more efficient fuel usage, carpool vans, or incentivized car pool lanes could be introduced into the model to further analyze possible $\mathrm{CO}_{2}$ emission reduction. Second, this analysis was limited to the San Diego metro area, but could be applied to other heavily congested urban areas. Finally, the data used in this project was publicly available from the California DOT and was based on road sensors. From this data, it is not possible to know if the vehicle was carrying multiple or single passengers, what kind of vehicle it was, or the vehicle gas efficiency. If there was a mechanism to collect data from the individual vehicle in real-time, more accurate predictive models could be created.

\section{Conclusion}

This capstone project demonstrates that predictive modelling techniques and data visualization tools can be successfully integrated in interdisciplinary programs helping to resolve environmental challenges like climate change. Environmental expertise from the MS Sustainability Management program working with the predictive modelling capability and data visualization techniques of MS Data Analytics students provided a practical engineering solution to traffic congestion that could be adopted and effectively used by urban planners and government transportation agencies in the near future.

Software applications platforms such as Tableau help analyze big data using predictive modeling, resulting in sustainable intelligence for more effective urban planning. A predictive model to reduce $\mathrm{CO}_{2}$ emissions providing sustainable intelligence for San Diego area highways traffic was demonstrated in this capstone project with different alternative modes of transportation. The reduction of $\mathrm{CO}_{2}$ improves the environment with the reduction of fossil fuel burning. Better economics is achieved not only because of less fuel consumption, but through increased productivity when drivers spend less time in traffic jams/congestion. Equity is achieved with less stress on drivers and better community health with better air to breathe, which also helps in the reduction of medical costs. Integrating data visualization and predictive modeling with these sustainability principles can assist urban transportation planners develop better environmentally sustainable cities in the future.

\section{Bibliography}

1. US History- Suburban Growth. http://www.ushistory.org/us/53b.asp ; retrieved January 9, 2016

2. Gas Price History. http://www.low-cost-gas.org/gasoline-price-history.html ; retrieved January 9, 2016

3. World Urbanization Prospects. http://esa.un.org/unpd/wup/FinalReport/WUP2014-Report.pdf ; retrieved January 8, 2016

4. The Atlantic. The American Commuter spends 38 hours a Year Stuck in Traffic. http://www.theatlantic.com/business/archive/2013/02/the-american-commuter-spends-38-hours-a-year-stuck-in-

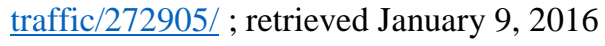


5. Environmental Protection Agency. Transportation Sector Emissions. http://www3.epa.gov/climatechange/ghgemissions/sources/transportation.html ; retrieved January 9, 2016

6. Vollmer, Derek. Pathways to Urban Sustainability: Lessons from the Atlanta Metropolitan Region: Summary of a Workshop. Washington, DC, USA: National Academies Press, 2011. ProQuest eLibrary. Web. 10 June 2015

7. California Department of Transpiration, Traffic Census Program. http://traffic-counts.dot.ca.gov/ ; retrieved January 15, 2016.

8. Kumyac, Richard, Carlson, T, Dulla, R \& Decker, S (2005) Procedure Manual for the COMMUTER Model: U.S. Environmental Protection Agency.

9. San Diego Traffic. http://www.hribar.com/san-diego-traffic-report.html . Retrieved January 16, 2016.

10. 2012 Geenhouse Gas Inventory for San Diego County and Projections http://www.sdforward.com/pdfs/DraftAppendixD-2012GHGInventoryForSDCountyAndProjections.pdf . Retrieved January 16, 2016 